Supporting Information For:

\title{
A Dual-Ion Battery Cathode via Oxidative Insertion of Anions in a Metal-Organic Framework
}

\author{
Michael L. Aubrey and Jeffrey R. Long* \\ Department of Chemistry, University of California, Berkeley, and Materials Sciences Division, \\ Lawrence Berkeley National Laboratory, Berkeley, CA 94720, USA
}

Journal of the American Chemical Society 


\section{Table of Contents}

- Calculation of Fe-Fe distances in metal-organic frameworks

- Calculation of anion sizes

- Scheme S1: Schematic of the electrochemical cell

- Figure S1: Fe-57 Mössbauer of $\mathrm{Fe}_{2}($ dobdc $)\left(\mathrm{PF}_{6}\right)(\mathrm{MeCN})_{\mathrm{y}}$

- Figure S2: PXRD of $\mathrm{Fe}_{2}(\mathrm{dobdc})\left(\mathrm{PF}_{6}\right)(\mathrm{MeCN})_{\mathrm{y}}$.

- Figure S3: Electrochemical oxidation of $\mathrm{Fe}_{2}$ (dobdc)

- Figure S4: Fe-57 Mössbauer specta before and after chemical oxidation

- Figure S5: PXRDs of electrochemically prepared sample of $\mathrm{Fe}_{2}(\mathrm{dobpdc})\left(\mathrm{BF}_{4}\right)_{\mathrm{x}}$

- Figure S6: PXRD of $\mathrm{Fe}_{2}(\mathrm{dobpdc})\left(\mathrm{PF}_{6}\right)_{\mathrm{x}}$ after 50 cycles at $1 \mathrm{C}$

- Figure S7: Le Bail refinement of $\mathrm{Fe}_{2}$ (dobpdc)

- Figure S8: Le Bail refinement of electrochemically oxidized $\mathrm{Fe}_{2}(\mathrm{dobpdc})\left(\mathrm{BF}_{4}\right)_{0.5}$

- Figure S9: Le Bail refinement of electrochemically oxidized $\mathrm{Fe}_{2}(\mathrm{dobpdc})\left(\mathrm{BF}_{4}\right)$

- Figure S10: Le Bail refinement of electrochemically oxidized $\mathrm{Fe}_{2}(\mathrm{dobpdc})\left(\mathrm{BF}_{4}\right)_{1.5}$

- Figure S11: Le Bail refinement of electrochemically oxidized $\mathrm{Fe}_{2}($ dobpdc $)\left(\mathrm{BF}_{4}\right)_{2}$

- Figure S12: PXRDs of chemically oxidized samples of $\mathrm{Fe}_{2}(\operatorname{dobpdc})\left(\mathrm{PF}_{6}\right)_{\mathrm{x}}$

- Figure S13: Le Bail refinement of chemically oxidized sample $\mathrm{Fe}_{2}(\mathrm{dobpdc})\left(\mathrm{PF}_{6}\right)$

- Figure S14: Le Bail refinement of chemically oxidized sample $\mathrm{Fe}_{2}(\mathrm{dobpdc})\left(\mathrm{PF}_{6}\right)_{2}$

- Figure S15: Le Bail refinement of $\mathrm{Mg}_{2}$ (dobpdc)

- Figure S16: Le Bail refinement of chemically oxidized $\mathrm{Mg}_{2}\left(\right.$ dobpdc) $\left(\mathrm{PF}_{6}\right)_{0.48}(\mathrm{MeCN})_{5.1}$

- Figure S17: Battery Summary with all discharge curves labled

- Table S1: ${ }^{57} \mathrm{Fe}$ Mössbauer fit parameters for chemically oxidized $\mathrm{Fe}_{2}($ dobdc $)\left(\mathrm{PF}_{6}\right) \cdot y \mathrm{MeCN}$.

- Table S2: Le Bail refined unit cells of $\mathrm{Fe}_{2}$ (dobdc) oxidized chemically.

- Table S3: Fe-Fe distances of selected minerals and iron based metal-organic frameworks with infinite chains of iron polyhedra

- Table S4: Calculated anion volumes from the crystal structures of the binary salts

- Table S5: Le Bail refined unit cells of $\mathrm{Fe}_{2}$ (dobpdc) oxidized electrochemically

- Table S6: Le Bail refined unit cells of $\mathrm{Fe}_{2}$ (dobpdc) oxidized chemically

- Table S7: Le Bail refined unit cells of $\mathrm{Mg}_{2}$ (dobpdc) oxidized chemically

- Table S8: Fe-57 Mössbauer fit parameters for chemically oxidized $\mathrm{Fe}_{2}$ (dobpdc) samples

- Table S9: Fe-57 Mössbauer fit parameters for electrochemically oxidized $\mathrm{Fe}_{2}(\mathrm{dobpdc})$ samples 


\section{Calculation of Fe-Fe distances in Metal-Organic Frameworks.}

All iron-iron distances were calculated from crystal information files (.cif) using the software Mercury in the CSD System sofware package by the Cambridge Crystallographic Data Centre. The structures $\mathrm{Fe}_{2}(\mathrm{dobdc}), \mathrm{Fe}_{2}(\mathrm{bdp})_{3}$, Ferric Gallate, Fe-Mil-53 (68), ilvaite and deerite can be found in the following references. ${ }^{1,2,6-9} \mathrm{Fe}-\mathrm{Met}-3$ is a metal triazolate framework with no structure file reported. ${ }^{10}$ The reported space group was Fd3-m and the lattice parameter for the iron phase was $16.652(1)$. There were two distinct iron sites in the unit cell: $4-3 \mathrm{~m}$ at $(0,0,0)$ and $3 \mathrm{~m}$ at $(1 / 8,1 / 8,1 / 8)$. This is the nearest iron-iron distance in the unit cell and can be calculated using the pythagorean theorem to give $3.61 \AA$.

\section{Calculation of anion sizes.}

Anion sizes were calculated from previously determined unit cells of their respective lithium salts. ${ }^{11-13}$ The tetrakis(perfluorophenyl)borate salt of lithium is not known as a pure binary in the Cambridge Structural Database. The unit cell of the thallium salt was used instead which

probably slightly overestimates the packing volume of this anion more so than the other anions. ${ }^{14}$ The calculation was done by dividing the reported unit cell volume by the number of anions in the unit cell. This was taken to be an estimate of the densest packing of anions and thusly their effective occupied volume in the $\mathrm{Fe}_{2}($ dobdpc) pore. 


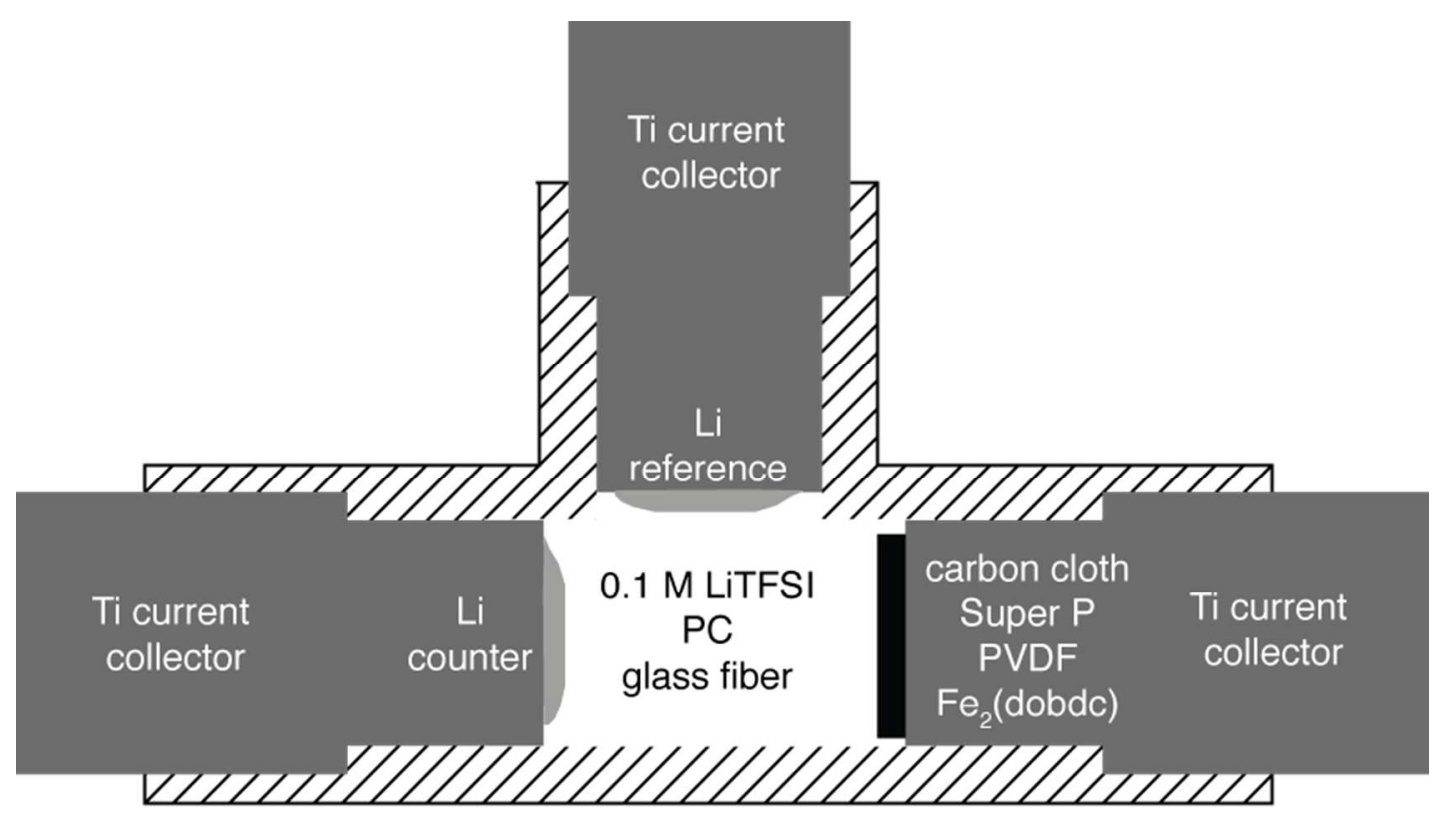

Scheme S1: Schematic of the electrochemical cell 


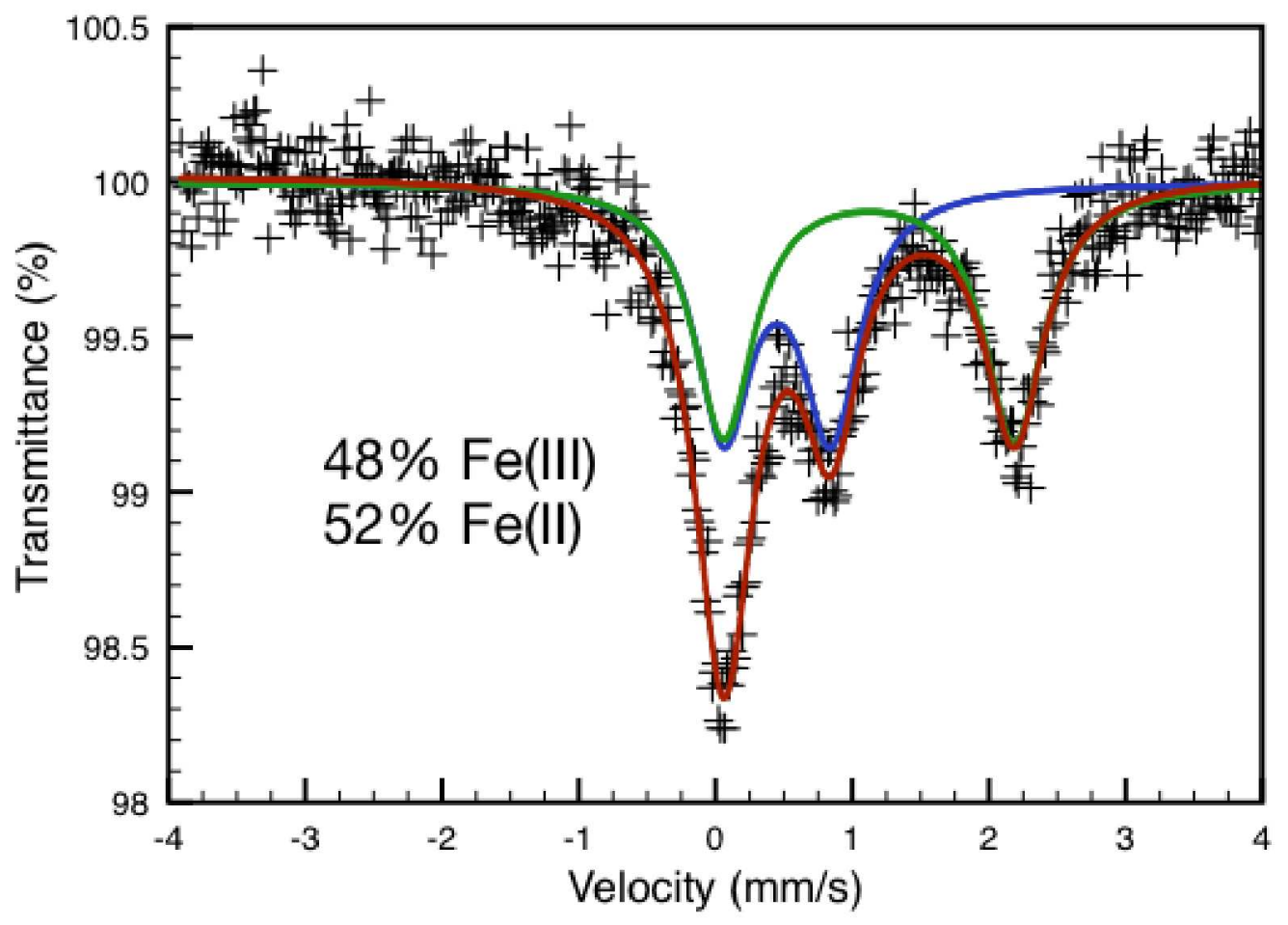

Figure S1: Fe-57 Mössbauer of $\mathrm{Fe}_{2}(\mathrm{dobdc})\left(\mathrm{PF}_{6}\right)(\mathrm{MeCN})_{y}$. Spectrum was collected at $100 \mathrm{~K}$. 


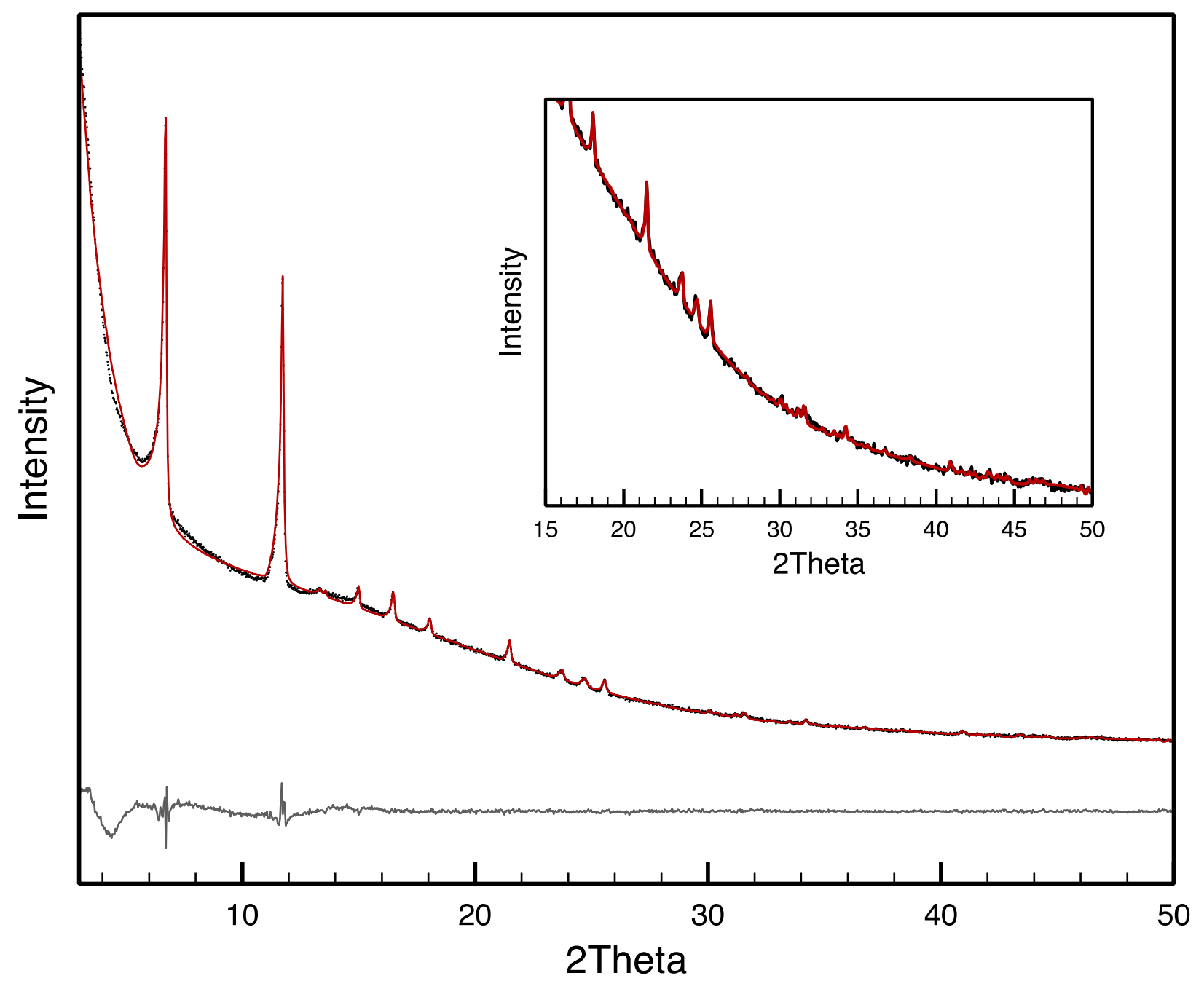

refined fit in red and the difference in grey. Inset shows the fit at high angle. No change in space group or new peaks are observed post oxidation. 


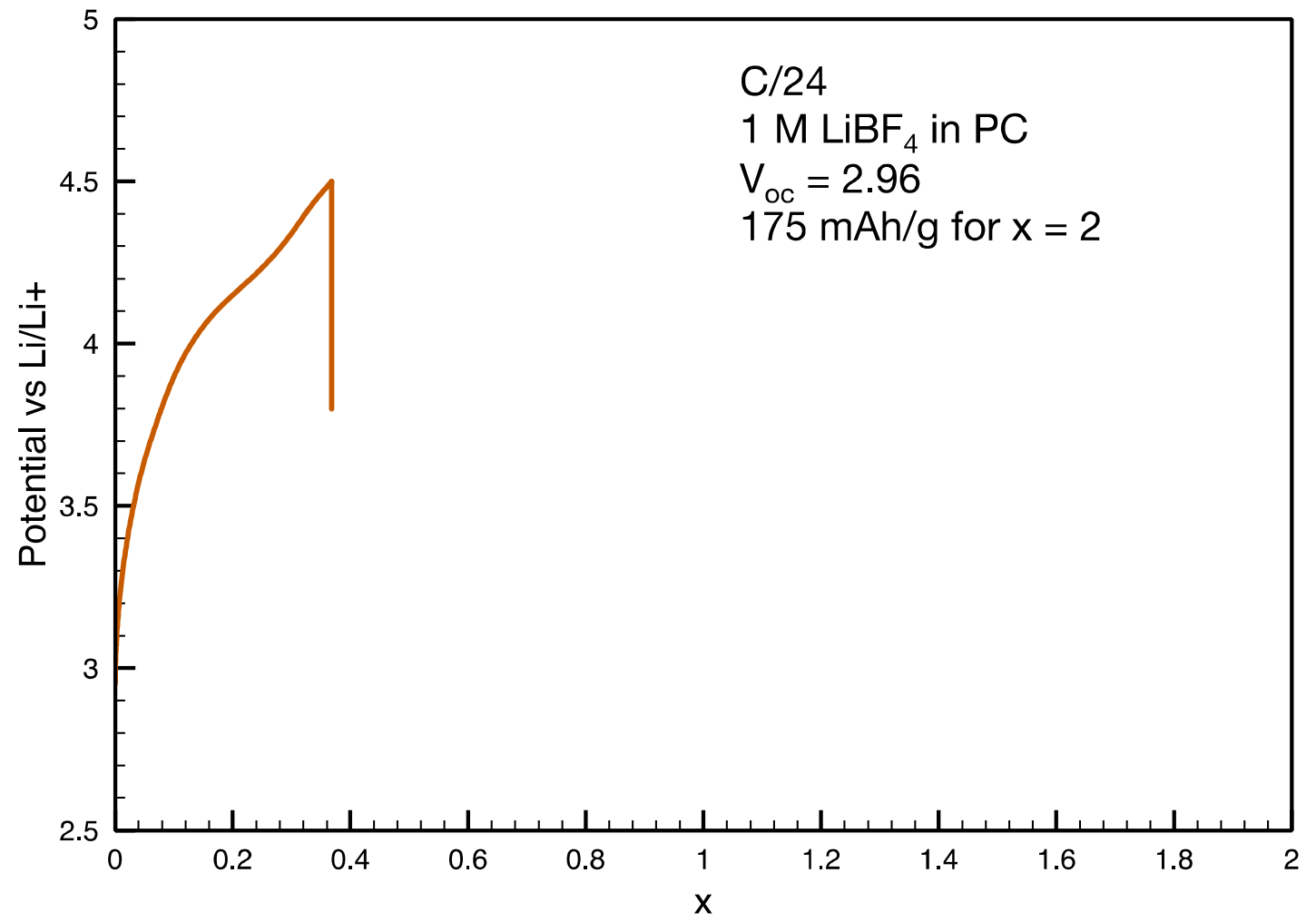

$\mathrm{Fe}_{2}(\mathrm{dobdc})\left(\mathrm{BF}_{4}\right)_{\mathrm{x}}$

Figure S3: Electrochemical oxidation of $\mathrm{Fe}_{2}$ (dobdc) with a lithium reference and counter electrode. In addition to the massive hysteresis this oxidation was not reversible with a $4.5 \mathrm{~V}$ potential limit. 


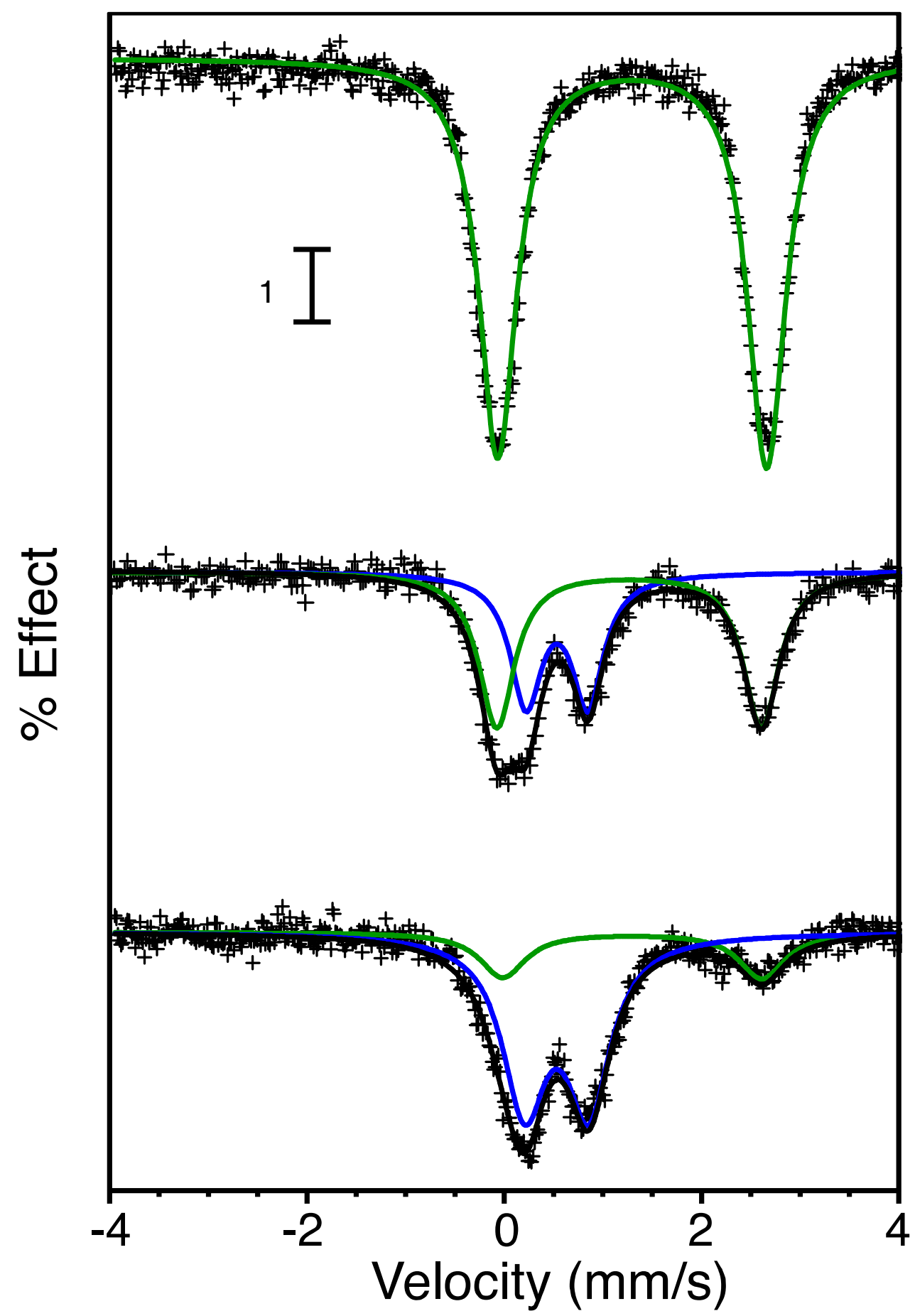

Figure S4. Fe-57 Mössbauer spectra of $\mathrm{Fe}_{2}$ (dobpdc) before (top) and after chemical oxidation with one equivalent (middle) and two equivalents (bottom) of thianthrenium hexafluorophosphate. Graph elements are: experimental data (pluses), HS-Fe(II) (green), HS-Fe(III) (blue) and fit (black). Velocities are reported relative to the isomer shift of $\alpha$-iron at $295 \mathrm{~K}$. 


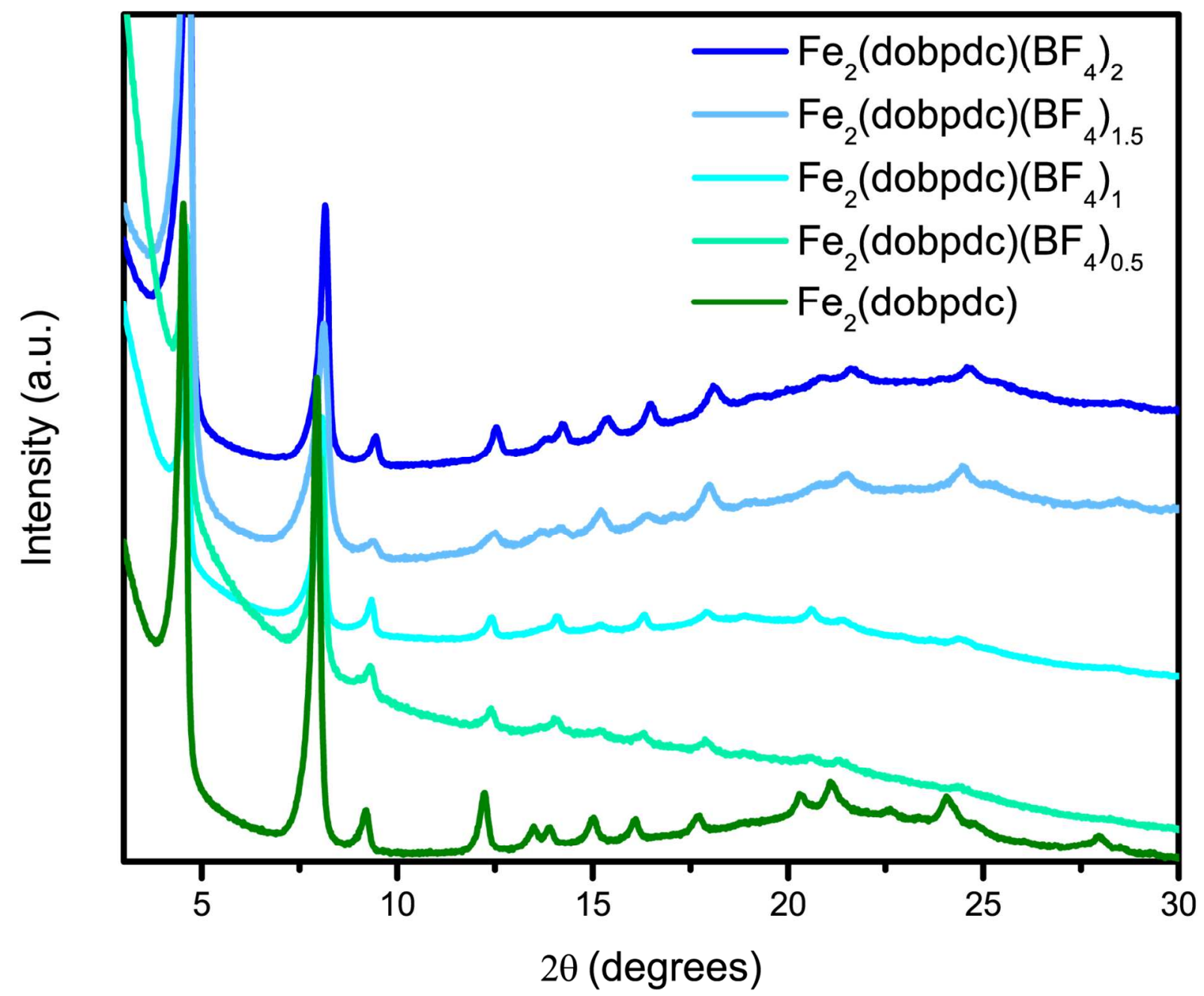

Figure S5: PXRDs of electrochemically prepared sample of $\mathrm{Fe}_{2}(\mathrm{dobpdc})\left(\mathrm{BF}_{4}\right)_{\mathrm{x}}$ 


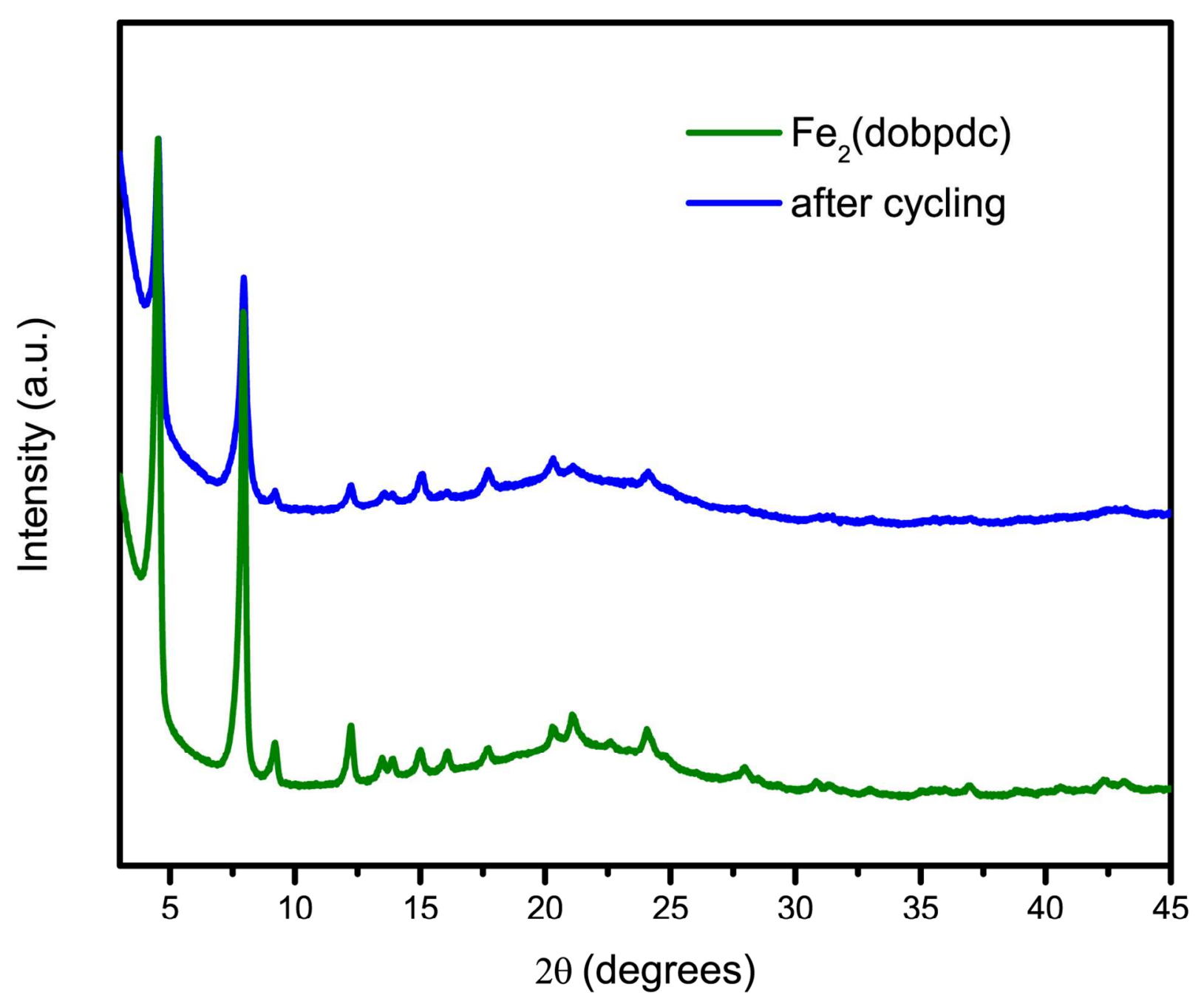

Figure S6: $\mathrm{PXRD}$ of $\mathrm{Fe}_{2}(\mathrm{dobpdc})\left(\mathrm{PF}_{6}\right)_{\mathrm{x}}$ before and after 50 cycles at $1 \mathrm{C}$ in $0.6 \mathrm{M} \mathrm{NaPF}_{6}$ in 30:70 EC:DEC with sodium reference and counter electrodes 


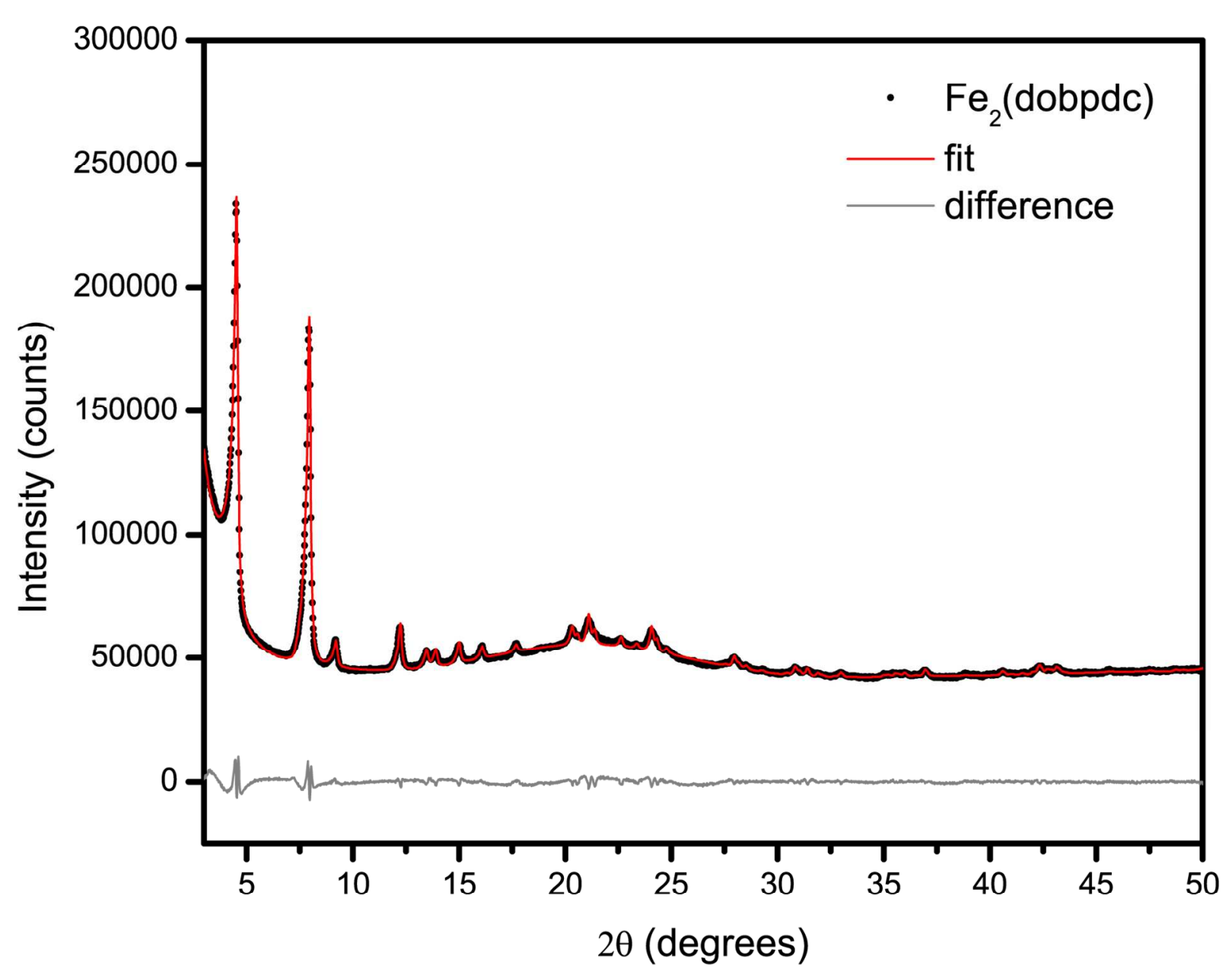

Figure S7: Le Bail refinement of $\mathrm{Fe}_{2}$ (dobpdc). The fit and difference are shown in red and grey. Experimental data is shown as black dots. 


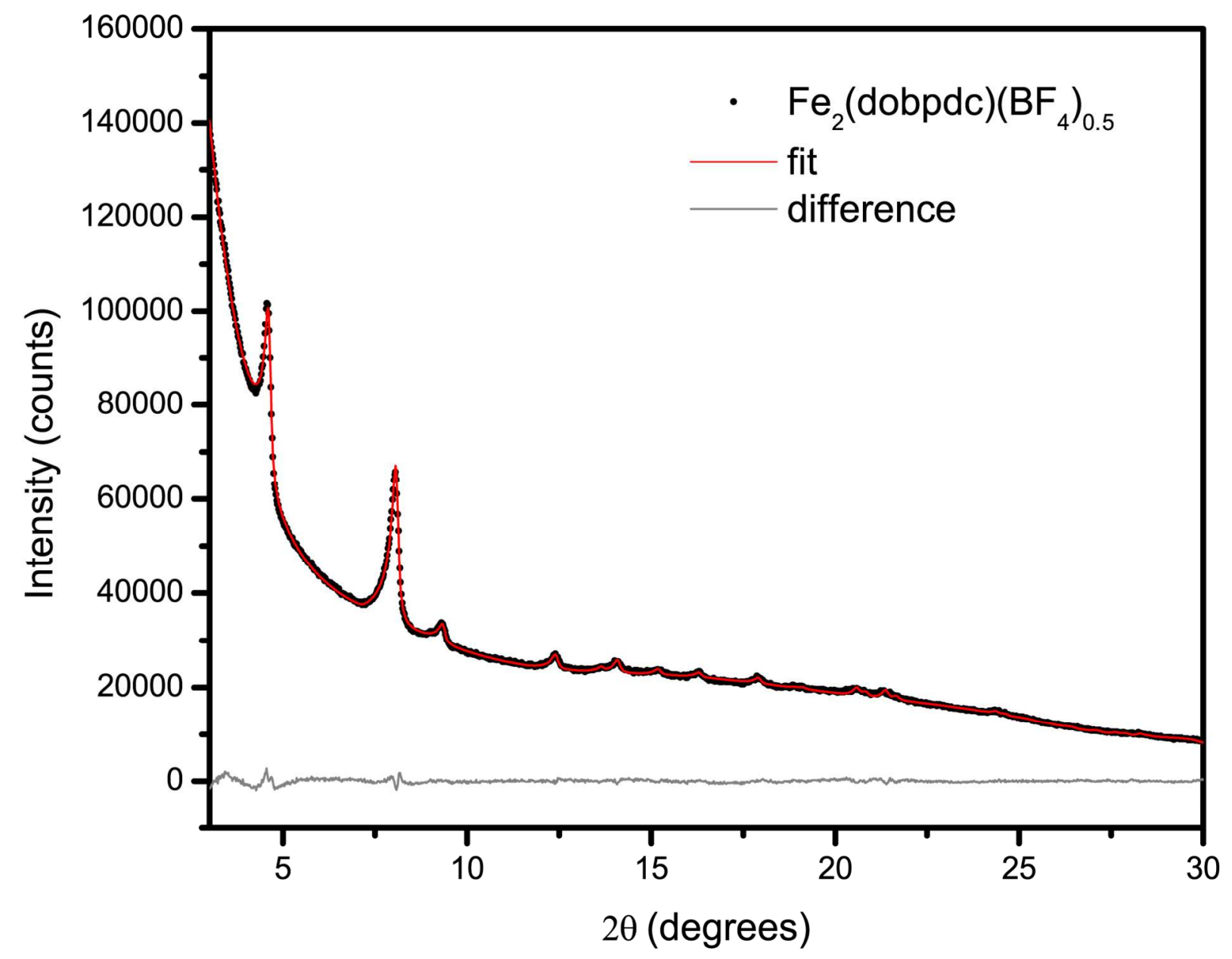

Figure S8: Le Bail refinement of electrochemically oxidized $\mathrm{Fe}_{2}($ dobpdc $)\left(\mathrm{BF}_{4}\right)_{0.5}$. The fit and difference are shown in red and grey. Experimental data is shown as black dots. 


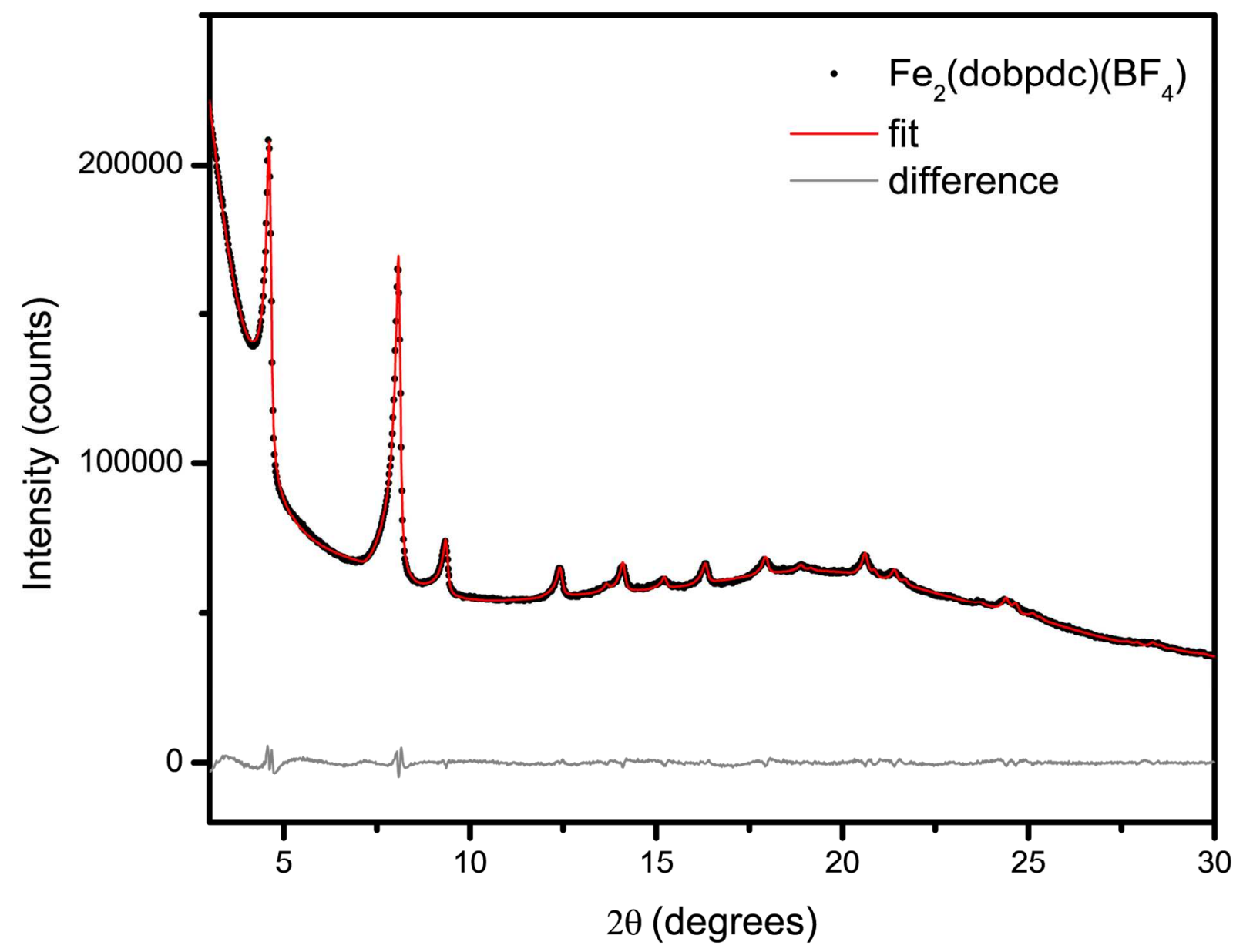

Figure S9: Le Bail refinement of electrochemically oxidized $\mathrm{Fe}_{2}($ dobpdc $)\left(\mathrm{BF}_{4}\right)$. The fit and difference are shown in red and grey. Experimental data is shown as black dots. 


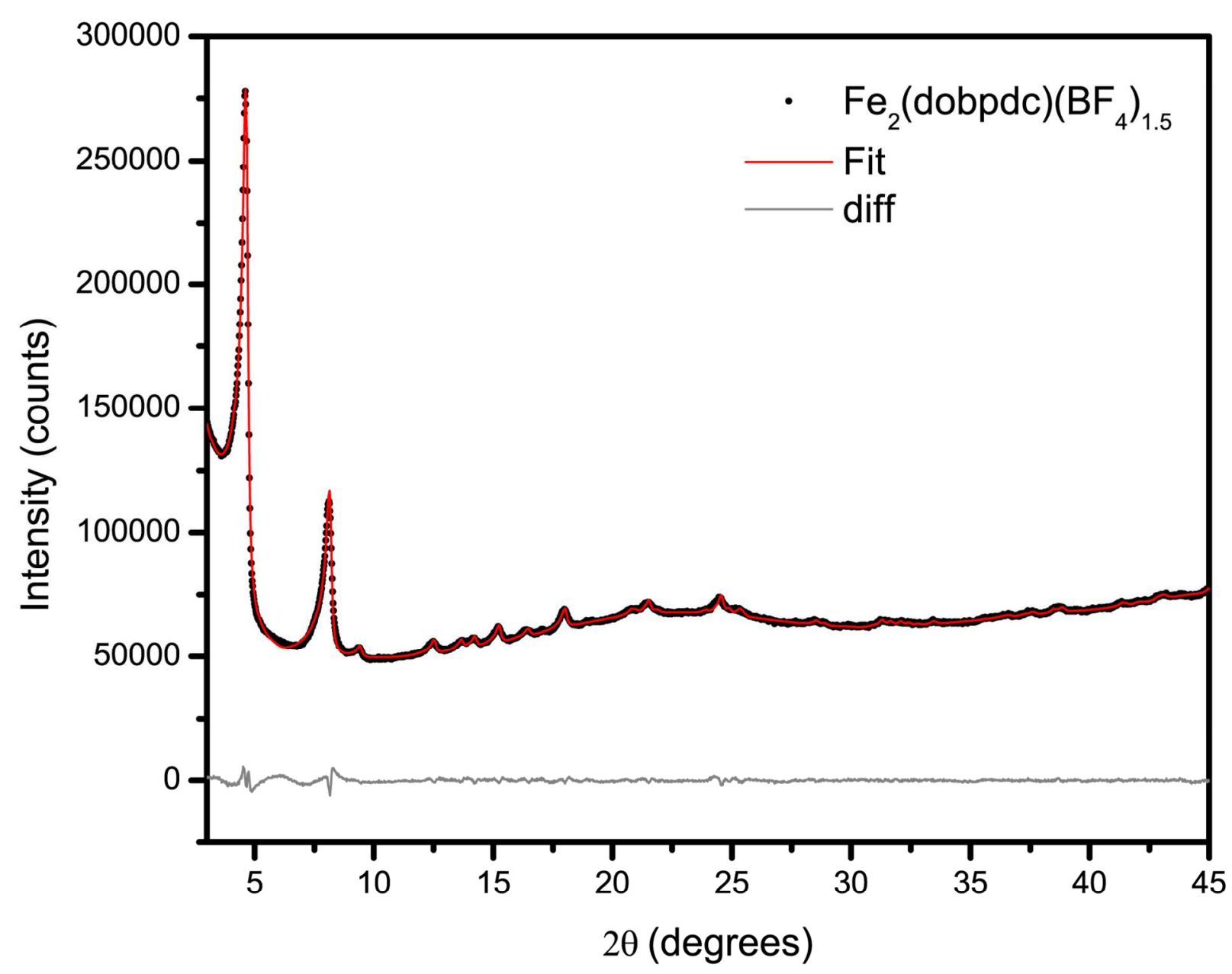

Figure S10: Le Bail refinement of electrochemically oxidized $\mathrm{Fe}_{2}(\operatorname{dobpdc})\left(\mathrm{BF}_{4}\right)_{1.5}$. The fit and difference are shown in red and grey. Experimental data is shown as black dots. 


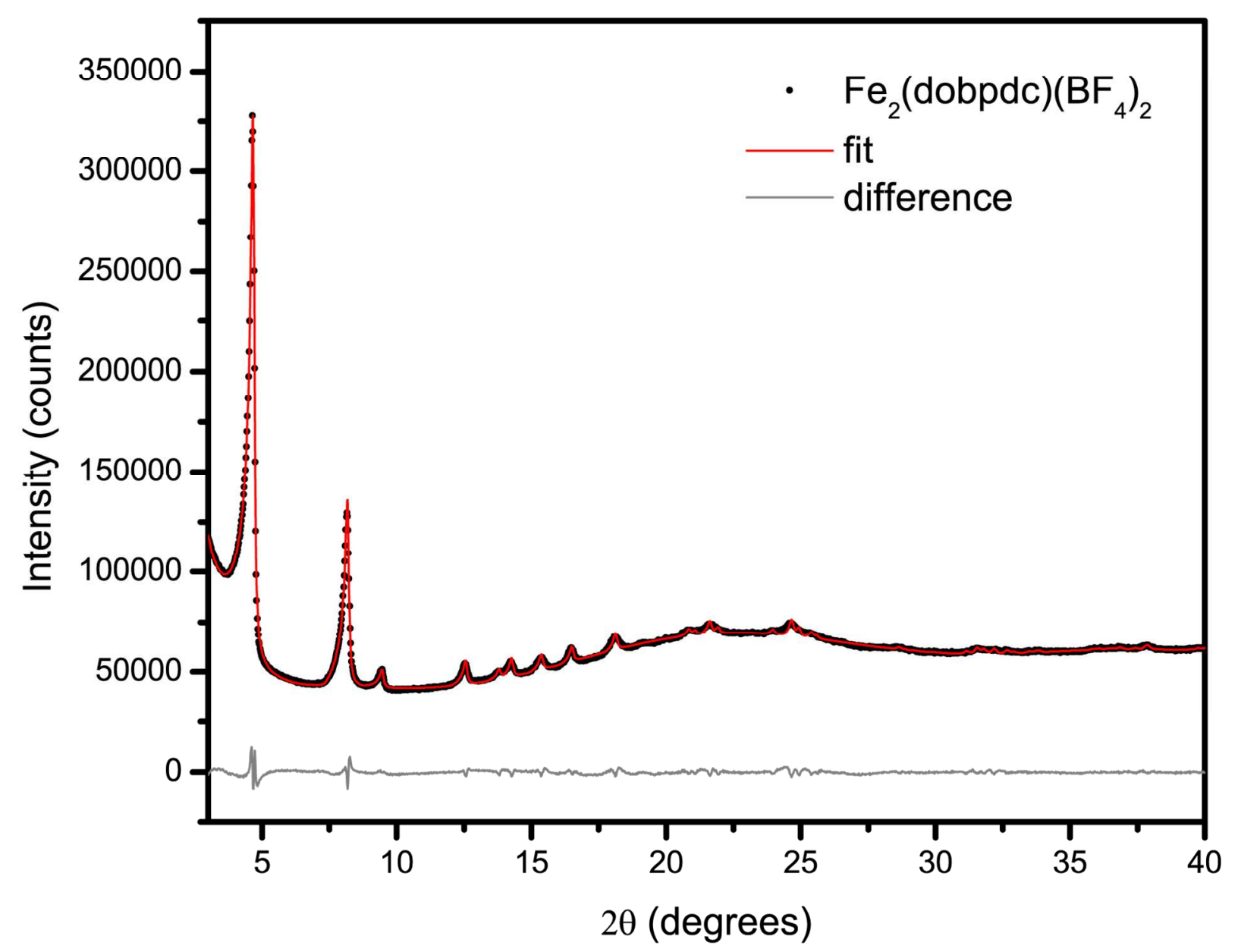

Figure S11: Le Bail refinement of electrochemically oxidized $\mathrm{Fe}_{2}(\mathrm{dobpdc})\left(\mathrm{BF}_{4}\right)_{2}$. The fit and difference are shown in red and grey. Experimental data is shown as black dots. 


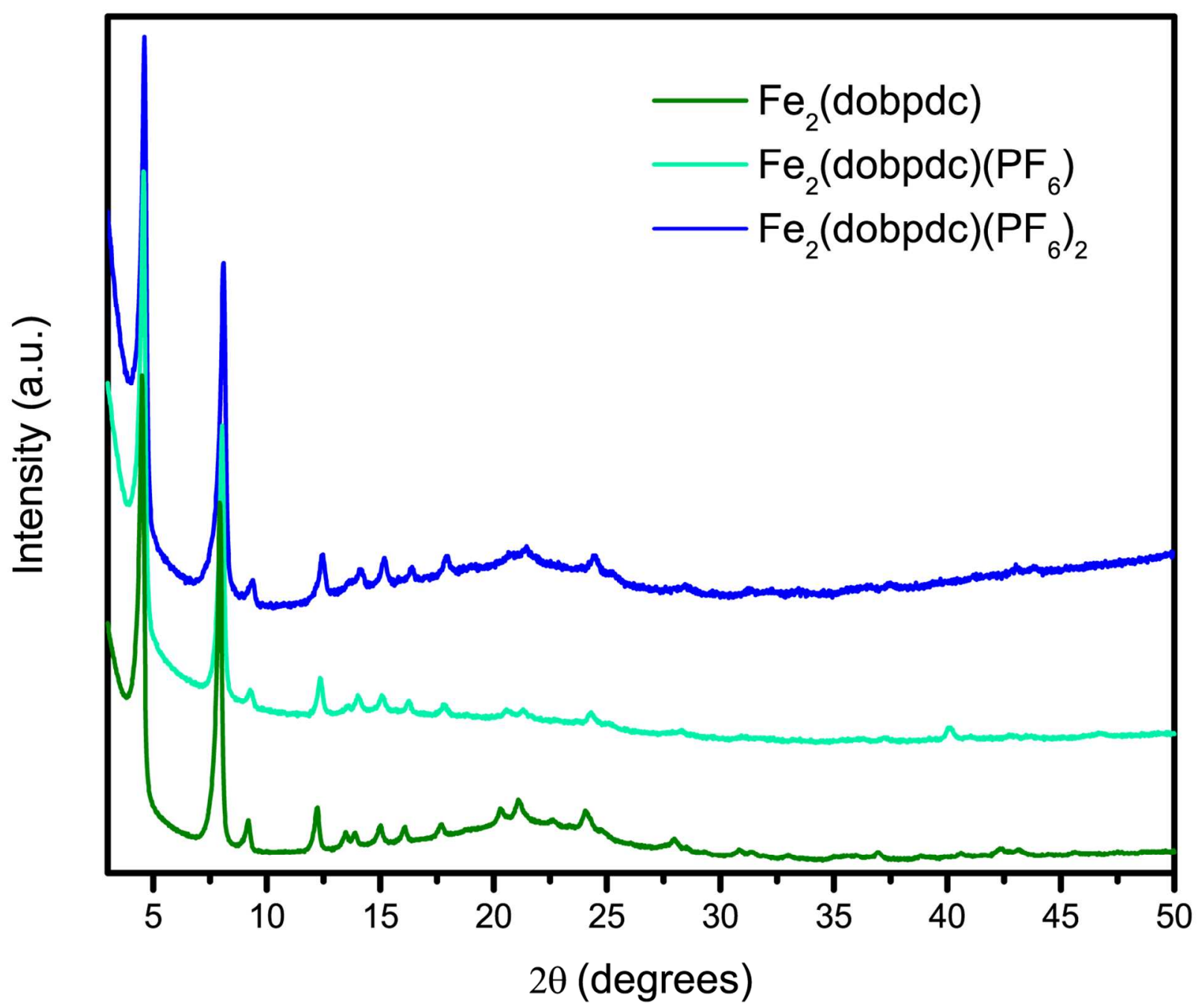

Figure S12: PXRDs of chemically oxidized samples of $\mathrm{Fe}_{2}(\mathrm{dobpdc})\left(\mathrm{PF}_{6}\right)_{\mathrm{x}}$ 


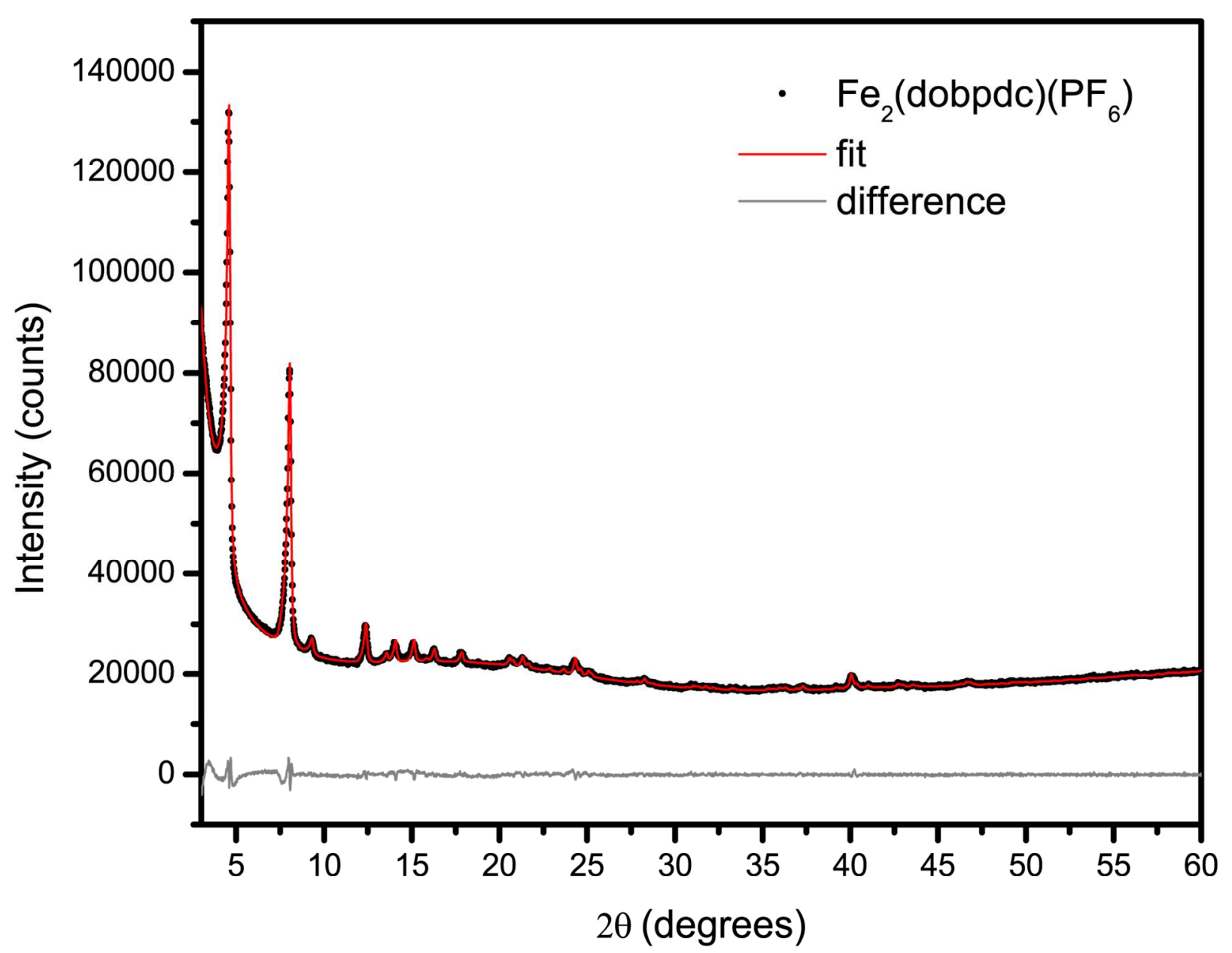

Figure S13: Le Bail refinement of chemically oxidized sample $\mathrm{Fe}_{2}(\mathrm{dobpdc})\left(\mathrm{PF}_{6}\right)$. The fit and difference are shown in red and grey. Experimental data is shown as black dots. 


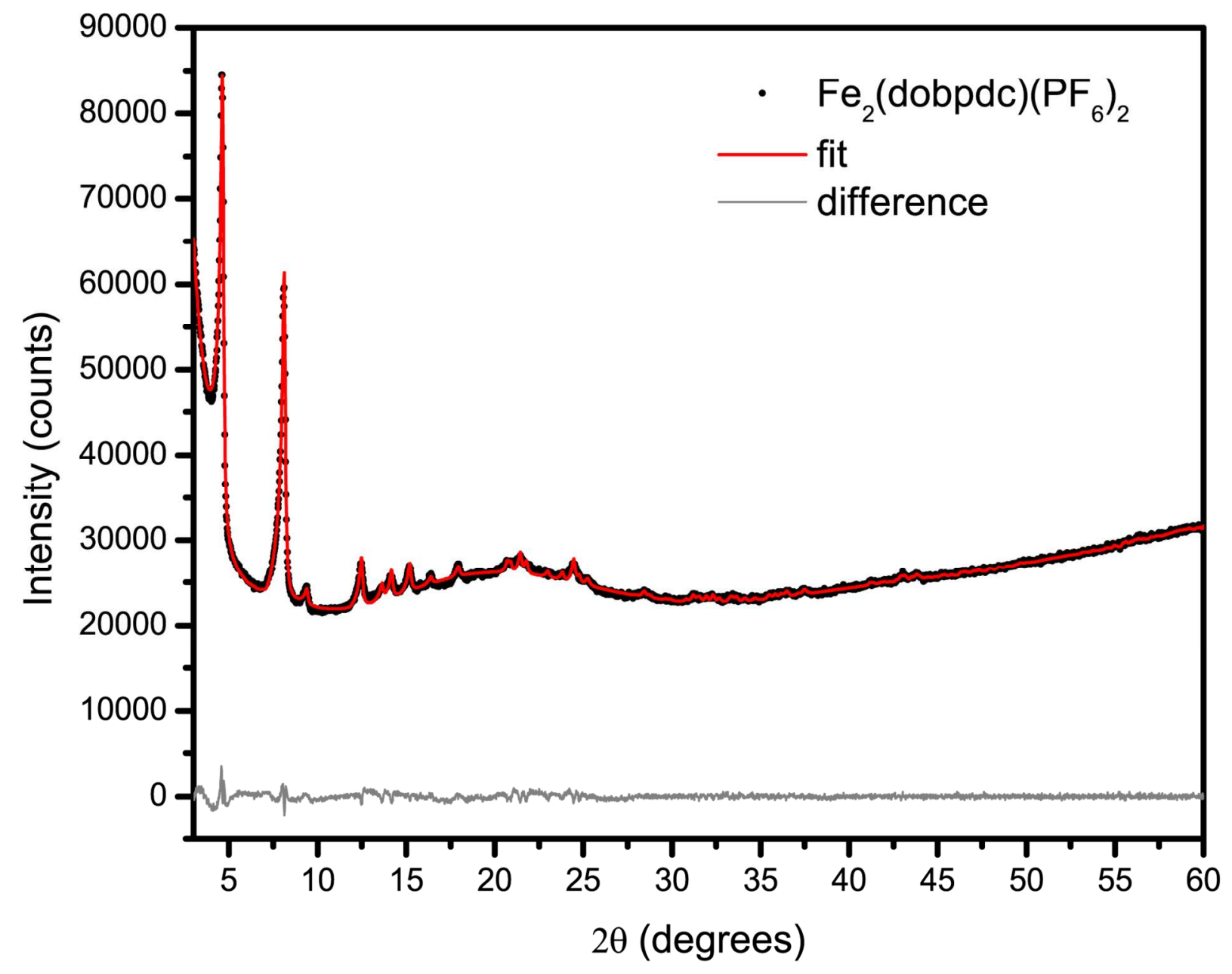

Figure S14: Le Bail refinement of chemically oxidized sample $\mathrm{Fe}_{2}(\mathrm{dobpdc})\left(\mathrm{PF}_{6}\right)_{2}$. The fit and difference are shown in red and grey. Experimental data is shown as black dots. 


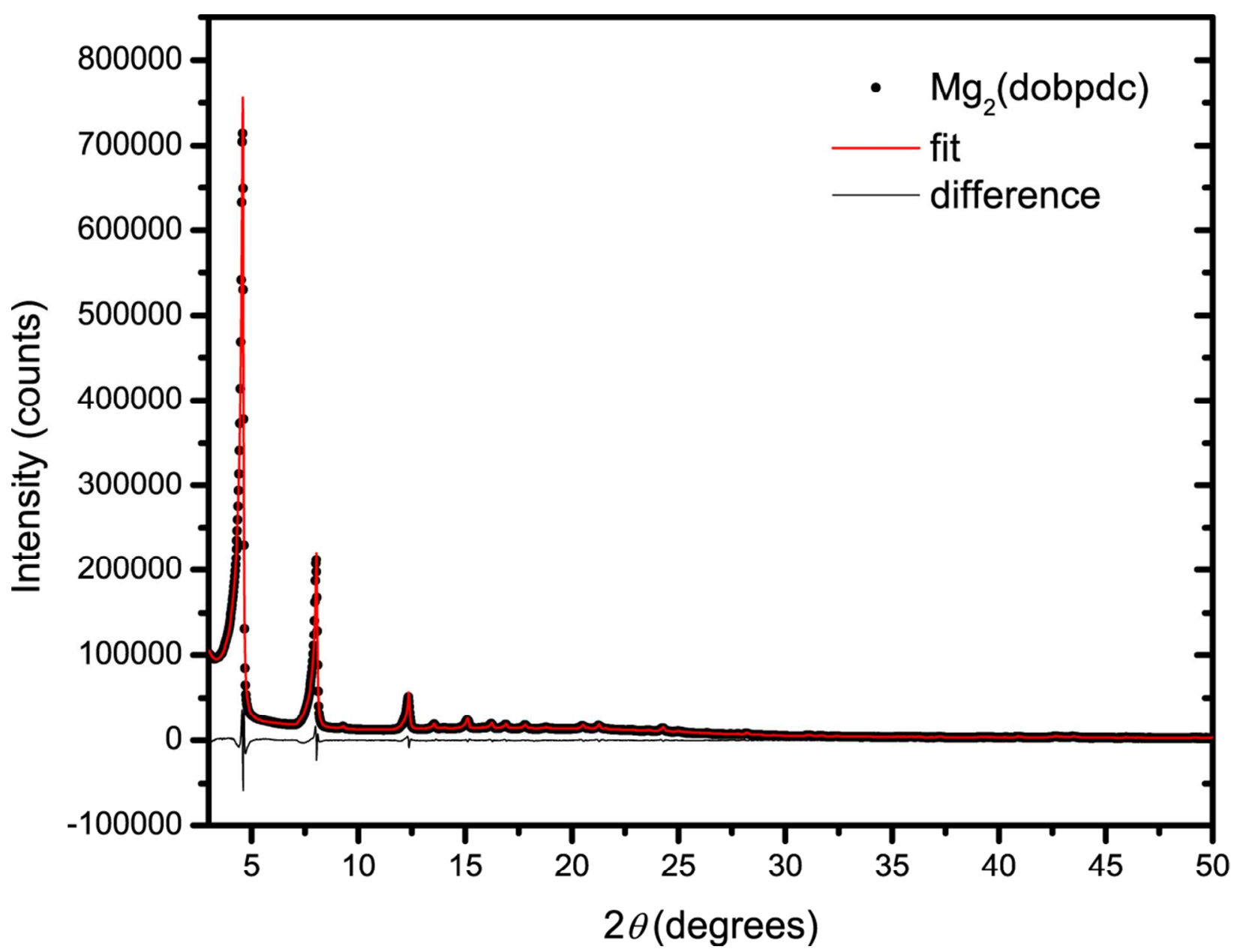

Figure S15: Le Bail refinement of $\mathrm{Mg}_{2}$ (dobpdc). The fit and difference are shown in red and grey. Experimental data is shown as black dots. 


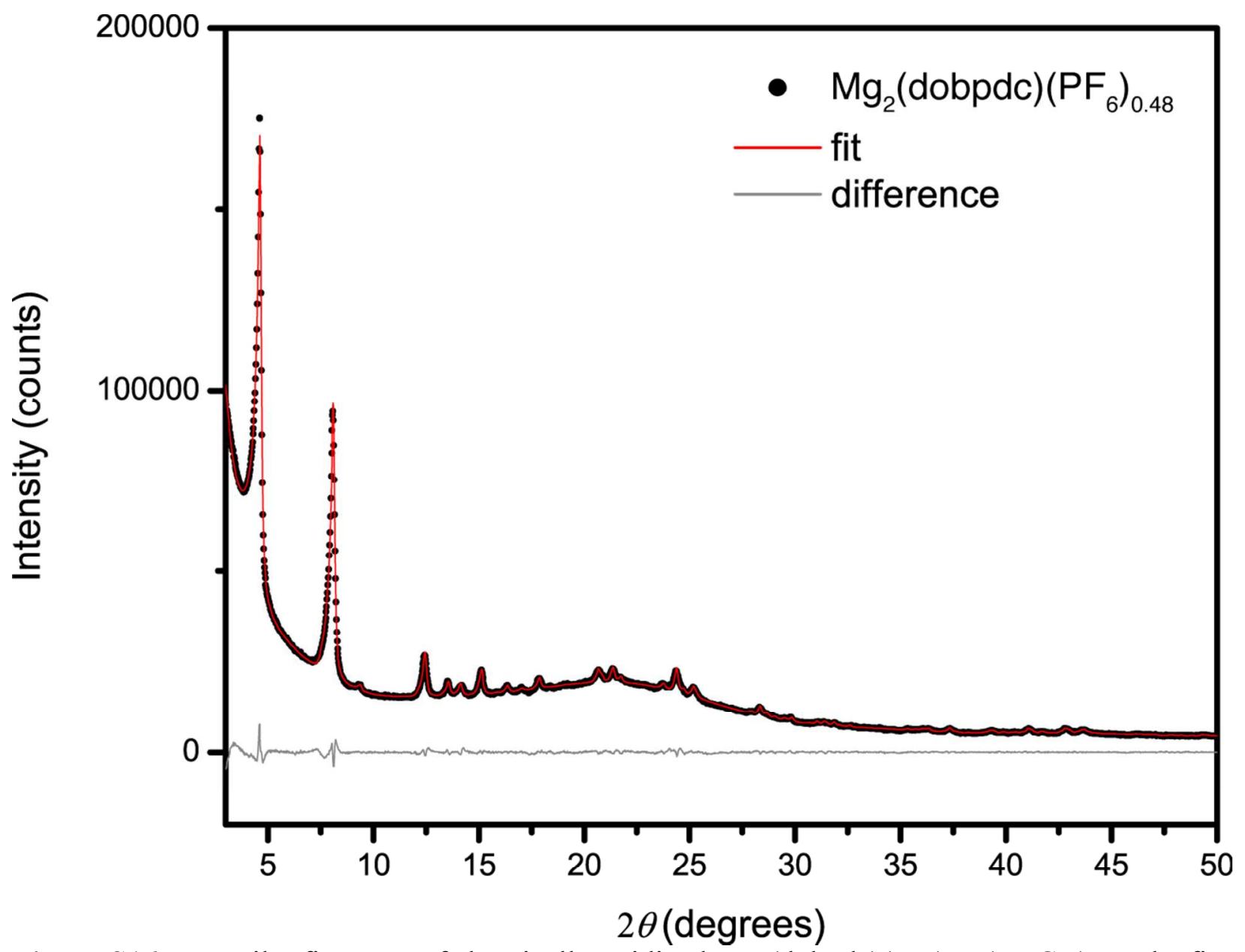

Figure S16: Le Bail refinement of chemically oxidized $\mathrm{Mg}_{2}(\mathrm{dobpdc})\left(\mathrm{PF}_{6}\right)_{0.48}(\mathrm{MeCN})_{5.1}$. The fit and difference are shown in red and grey. Experimental data is shown as black dots. 


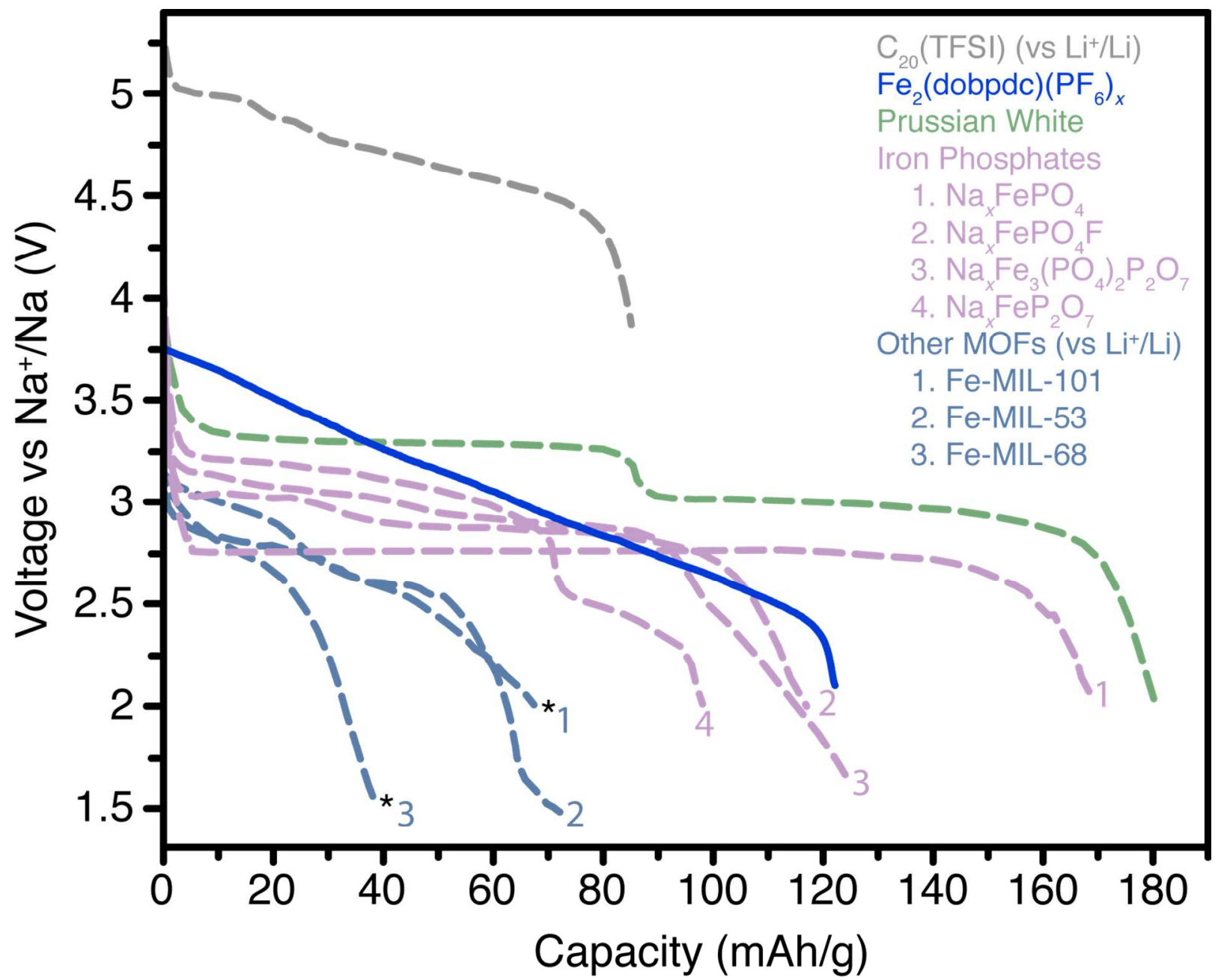

Figure S17: Battery Summary with all discharge curves labled. Data for these curves can be found in references. ${ }^{15-22}$ 
Table S1: ${ }^{57} \mathrm{Fe}$ Mössbauer fit parameters for chemically oxidized $\mathrm{Fe}_{2}(\mathrm{dobdc})\left(\mathrm{PF}_{6}\right) \bullet \mathrm{yMeCN}$. Displayed stoichiometry is as determined by the stoichiometry of the reaction.

\begin{tabular}{c|cc} 
& \multicolumn{2}{|c}{$\mathrm{Fe}_{2}(\mathrm{dobdc})\left(\mathrm{PF}_{6}\right)$} \\
\hline Assignment & $\mathrm{HS}-\mathrm{Fe}(\mathrm{II})$ & $\mathrm{HS}-\mathrm{Fe}(\mathrm{III})$ \\
$\delta$ & 1.121 & 0.466 \\
$\Delta_{\mathrm{E}}$ & 2.111 & 0.777 \\
$\Gamma$ & 0.461 & 0.544 \\
$\%$ & 52.0 & 48.0
\end{tabular}


Table S2: Le Bail refined unit cells of $\mathrm{Fe}_{2}$ (dobdc) oxidized chemically. Dimensions are given in Ångstroms. Stoichiometry is as determined by the reagents added to the reaction. Unit cell parameters of the all ferrous phase were reported previously. ${ }^{6}$

\begin{tabular}{c|cc} 
& $\mathrm{Fe}_{2}(\mathrm{dobdc})$ & $\mathrm{Fe}_{2}(\mathrm{dobdc})\left(\mathrm{PF}_{6}\right)$ \\
\hline Space Group & $\mathrm{R} 3$ & $\mathrm{R} 3$ \\
$\alpha$ & 26.098 & $25.808(3)$ \\
$\mathrm{C}$ & 6.8512 & $6.875(2)$ \\
$\mathrm{V}$ & 4041.2 & $3966(2)$ \\
$\mathrm{r}_{\mathrm{wp}}$ & & 1.791 \\
$\mathrm{r}_{\mathrm{p}}$ & & 1.335
\end{tabular}


Table S3: Fe-Fe distances of selected minerals and iron based metal-organic frameworks with infinite chains of iron polyhedra (ref. 1,2,6-10).

Framework

Fe-MOF-74

Fe-MIL-53 (68)

Fe-MET-3

Ferric Gallate

$\mathrm{Fe}_{2}(\mathrm{bdp})_{3}$

Ilvaite

Deerite
Fe-Fe distance (Å)

3.04

3.45

3.61

3.72

3.85

$2.83,3.03,3.01,3.15,3.25$

3.11-3.31 (9) 
Table S4: Calculated anion volumes from the crystal structures of the binary salts. Only the thallium salt of tetrakis-(perfluorophenyl)borate has a known crystal structure without cocrystalized solvent. As such the anion volume may be over estimated.

$\begin{array}{ccccc}\text { Salt } & \begin{array}{c}\text { Space } \\ \text { Group }\end{array} & \mathbf{Z} & \begin{array}{c}\text { Cell Volume } \\ \left(\AA^{3}\right)\end{array} & \begin{array}{c}\text { Volume per } \\ \text { anion }\left(\AA^{3}\right)\end{array} \\ \mathrm{LiBF}_{4} & \mathrm{P}_{1} 2_{1} & 3 & 228.02 & 76 \\ \mathrm{LiPF}_{6} & \mathrm{R}-3 & 3 & 266.65 & 88.88 \\ \mathrm{LiTFSI} & \text { Pnaa } & 4 & 848.616 & 212.154 \\ \mathrm{TIB}\left(\mathrm{C}_{6} \mathrm{~F}_{5}\right)_{4} & \text { I34d } & 12 & 6962.4 & 580.2\end{array}$


Table S5: Le Bail refined unit cells of $\mathrm{Fe}_{2}($ dobpdc) oxidized electrochemically. Dimensions are given in Ångstroms.

\begin{tabular}{c|ccccc}
\hline Phase (echem) & $\mathrm{Fe}_{2}(\mathrm{dobpdc})$ & $\mathrm{Fe}_{2}(\mathrm{dobpdc})\left(\mathrm{BF}_{4}\right)_{0.5}$ & $\mathrm{Fe}_{2}(\mathrm{dobpdc})\left(\mathrm{BF}_{4}\right)_{1}$ & $\mathrm{Fe}_{2}(\mathrm{dobpdc})\left(\mathrm{BF}_{4}\right)_{1.5}$ & $\mathrm{Fe}_{2}(\mathrm{dobpdc})\left(\mathrm{BF}_{4}\right)_{2}$ \\
\hline space group & 154 & 154 & 154 & 154 & 154 \\
$\mathrm{a}$ & $21.839(2)$ & $21.580(5)$ & $21.551(2)$ & $21.357(4)$ & $21.325(2)$ \\
$\mathrm{c}$ & $6.925(1)$ & $6.850(3)$ & $6.835(2)$ & $6.842(2)$ & $6.7754(17)$ \\
$\mathrm{V}$ & $2806.4(7)$ & $2762(2)$ & $2749.2(11)$ & $2702.7(14)$ & $2668.4(9)$ \\
$\mathrm{r}_{\text {wp }}$ & 1.643 & 1.160 & 1.015 & 1.095 & 1.480 \\
$\mathrm{r}_{\mathrm{p}}$ & 1.246 & 0.934 & 0.797 & 0.732 & 1.035
\end{tabular}


Table S6: Le Bail refined unit cells of $\mathrm{Fe}_{2}$ (dobpdc) oxidized chemically, stoichiometry was estimated from Mössbauer fits. Dimensions are given in Ångstroms.

\begin{tabular}{c|ccc}
\hline Phase (chem) & $\mathrm{Fe}_{2}$ (dobpdc) & $\mathrm{Fe}_{2}(\mathrm{dobpdc})\left(\mathrm{PF}_{6}\right)_{0.84}$ & $\mathrm{Fe}_{2}$ (dobpdc) $\left(\mathrm{PF}_{6}\right)_{1.56}$ \\
\hline space group & 154 & 154 & 154 \\
$\mathrm{a}$ & $21.839(2)$ & $21.573(2)$ & $21.460(3)$ \\
$\mathrm{C}$ & $6.925(1)$ & $6.881(8)$ & $6.860(1)$ \\
$\mathrm{V}$ & $2806.4(7)$ & $2773(4)$ & $2736(1)$ \\
$\mathrm{r}_{\mathrm{wp}}$ & 1.643 & 1.415 & 1.122 \\
$\mathrm{r}_{\mathrm{p}}$ & 1.246 & 1.045 & 0.846
\end{tabular}


Table S7: Le Bail refined unit cells of $\mathrm{Mg}_{2}$ (dobpdc) oxidized chemically. Dimensions are given in Ångstroms. Stoichiometry was estimated from elemental analysis.

\begin{tabular}{c|cc}
\hline Phase & $\mathrm{Mg}_{2}$ (dobpdc) & $\mathrm{Mg}_{2}($ dobpdc $)\left(\mathrm{PF}_{6}\right)_{0.48}$ \\
\hline space group & 154 & 154 \\
$\mathrm{a}$ & $21.635(2)$ & $21.5151(15)$ \\
$\mathrm{C}$ & $6.890(1)$ & $6.9031(7)$ \\
$\mathrm{V}$ & $2793.1(8)$ & $2767.4(6)$ \\
$\mathrm{r}_{\mathrm{wp}}$ & 4.607 & 1.894 \\
$\mathrm{r}_{\mathrm{p}}$ & 2.687 & 1.45
\end{tabular}


Table S8. Fe-57 Mössbauer fit parameters for chemically oxidized samples. The stoichiometries displayed were determined from the stoichiometry of the reaction. Isomer shifts are reported relative to $\alpha$-iron at $295 \mathrm{~K}$.

\begin{tabular}{c|c|cc|cc} 
& $\mathrm{Fe}_{2}(\mathrm{dobpdc})$ & $\mathrm{Fe}_{2}(\mathrm{dobpdc})\left(\mathrm{PF}_{6}\right)$ & $\mathrm{Fe}_{2}(\mathrm{dobpdc})\left(\mathrm{PF}_{6}\right)_{2}$ \\
\hline Assignment & $\mathrm{HS}-\mathrm{Fe}(\mathrm{II})$ & $\mathrm{HS}-\mathrm{Fe}(\mathrm{II})$ & $\mathrm{HS}-\mathrm{Fe}(\mathrm{III})$ & $\mathrm{HS}-\mathrm{Fe}(\mathrm{II})$ & $\mathrm{HS}-\mathrm{Fe}(\mathrm{III})$ \\
$\delta(\mathrm{mm} / \mathrm{s})$ & 1.297 & 1.265 & 0.535 & 1.298 & 0.531 \\
$\Delta_{\mathrm{E}}(\mathrm{mm} / \mathrm{s})$ & 2.725 & 2.681 & 0.626 & 2.627 & 0.652 \\
$\Gamma(\mathrm{mm} / \mathrm{s})$ & 0.464 & 0.437 & 0.391 & 0.563 & 0.541 \\
$\%$ & 100 & 57 & 43 & 21.7 & 78.7
\end{tabular}


Table S9. Fe-57 Mössbauer fit parameters for electrochemically oxidized samples. The displayed stoichiometries were determined by current integration. Isomer shifts are reported relative to $\alpha$-iron at $295 \mathrm{~K}$.

\begin{tabular}{c|c|cc|ccc|c} 
& $\mathrm{Fe}_{2}$ (dobpdc) & \multicolumn{2}{|c|}{$\mathrm{Fe}_{2}(\mathrm{dobpdc})\left(\mathrm{BF}_{4}\right)_{1}$} & \multicolumn{3}{|c|}{$\mathrm{Fe}_{2}$ (dobpdc)(BF $)_{2}$} & $\begin{array}{c}\mathrm{Fe}_{2} \text { (dobpdc) } \\
\text { (post discharge) }\end{array}$ \\
\hline Assignment & $\mathrm{HS}-\mathrm{Fe}(\mathrm{II})$ & $\mathrm{HS}-\mathrm{Fe}(\mathrm{II})$ & $\mathrm{HS}-\mathrm{Fe}(\mathrm{III})$ & $\mathrm{HS}-\mathrm{Fe}(\mathrm{II})$ & $\mathrm{HS}-\mathrm{Fe}(\mathrm{III})$ & $\mathrm{HS}-\mathrm{Fe}(\mathrm{III})$ & $\mathrm{HS}-\mathrm{Fe}(\mathrm{II})$ \\
$\delta(\mathrm{mm} / \mathrm{s})$ & 1.297 & 1.286 & 0.536 & 1.270 & 0.552 & 0.507 & 1.300 \\
$\Delta_{\mathrm{E}}(\mathrm{mm} / \mathrm{s})$ & 2.725 & 2.718 & 0.641 & 2.65 & 1.051 & 0.508 & 2.622 \\
$\Gamma(\mathrm{mm} / \mathrm{s})$ & 0.464 & 0.481 & 0.383 & 0.41 & 0.397 & 0.325 & 0.454 \\
$\%$ area & 100 & 49.6 & 50.4 & 6.8 & 40.4 & 52.8 & 100
\end{tabular}




\section{References}

(1) Burns, R. G. Annu. Rev. Earth Planet Sci. 1981, 9, 345-383.

(2) Amthauer, G.; Rossman, G. R. Phys. Chem. Miner. 1984, 11, 37-51.

(6) Bloch, E. D.; Murray, L. J.; Queen, W. L.; Chavan, S.; Maximoff, S. N.; Bigi, J. P.; Krishna, R.; Peterson, V. K.; Grandjean, F.; Long, G. J.; Smit, B.; Bordiga, S.; Brown, C. M.; Long, J. R. J. Am. Chem. Soc. 2011, 133, 14814-12822.

(7) Herm, Z. R.; Wiers, B. M.; Mason, J. A.; van Baten, J. M.; Hudson, M. R.; Zajdel, P.; Brown, C. M.; Masciocchi, N.; Krishna, R.; Long, J. R. Science 2013, 340, 960-964.

(8) Feller, R. K.; Cheetham, A. K. Solid State Sci. 2006, 8, 1121-1125.

(9) Devic, T.; Horcajada, P.; Serre, C.; Salles, F.; Maurin, G.; Moulin, B.; Heurtaux, D.; Clet, G.; Vimont, A.; Greneche, J. M.; Le Ouay, B.; Moreau, F.; Magnier, E.; Filinchuk, Y.;

Marrot, J.; Lavalley, J. C.; Daturi, M.; Ferey, G. J. Am. Chem. Soc. 2010, 132, 1127-1136.

(10) Gandara, F.; Uribe-Romo, F. J.; Britt, D. K.; Furukawa, H.; Lei, L.; Cheng, R.; Duan, X. F.; O'Keeffe, M.; Yaghi, O. M. Chem.-Eur. J. 2012, 18, 10595-10601.

(11) Matsumoto, K.; Hagiwara, R.; Mazej, Z.; Goreshnik, E.; Zemva, B. J. Phys. Chem. B 2006, 110, 2138-2141.

(12) Rohr, C.; Kniep, R. Z. Naturforsch B. 1994, 49, 650-654.

(13) Nowinski, J. L.; Lightfoot, P.; Bruce, P. G. J. Mater. Chem. 1994, 4, 1579-1580.

(14) Parvez, M.; Piers, W. E.; Ghesner, I. Acta Crystallogr. E 2005, 61, M1801-M1803.

(15) Oh, S.-M.; Myung, S.-T.; Hassoun, J.; Scrosati, B.; Sun, Y.-K. Electrochem. Commun. 2012, 22, 149-152.

(16) Wang, L.; Song, J.; Qiao, R.; Wray, L. A.; Hossain, M. A.; Chuang, Y.-D.; Yang, W.; Lu, Y.; Evans, D.; Lee, J.-J.; Vail, S.; Zhao, X.; Nishijima, M.; Kakimoto, S.; Goodenough, J. B. J. Am. Chem. Soc. 2015, 137, 2548-2554.

(17) Barpanda, P.; Liu, G.; Ling, C. D.; Tamaru, M.; Avdeev, M.; Chung, S.-C.; Yamada, Y.; Yamada, A. Chem. Mater. 2013, 25, 3480-3487.

(18) Pan, H.; Hu, Y.-S.; Chen, L. Energy Environ. Sci. 2013, 6, 2338-2360.

(19) Kawabe, Y.; Yabuuchi, N.; Kajiyama, M.; Fukuhara, N.; Inamasu, T.; Okuyama, R.; Nakai, I.; Komaba, S. Electrochem. Commun. 2011, 13, 1225-1228.

(20) Shin, J.; Kim, M.; Cirera, J.; Chen, S.; Halder, G. J.; Yersak, T. A.; Paesani, F.; Cohen, S. M.; Meng, Y. S. J. Mater. Chem. A 2015, 3, 4738-4744.

(21) Ferey, G.; Millange, F.; Morcrette, M.; Serre, C.; Doublet, M. L.; Greneche, J. M.; Tarascon, J. M. Angew. Chem. -Int. Ed. 2007, 46, 3259-3263.

(22) Fateeva, A.; Horcajada, P.; Devic, T.; Serre, C.; Marrot, J.; Greneche, J. M.; Morcrette, M.; Tarascon, J. M.; Maurin, G.; Ferey, G. Eur. J. Inorg. Chem. 2010, 3789-3794. 